\title{
REMARKS ON SOME MINIMALIST ACCOUNTS FOR BINDING
}

\author{
Cilene Rodrigues ${ }^{{ }^{\star}}$
}

${ }^{1}$ Pontifícia Universidade Católica do Rio de Janeiro, Rio de Janeiro, RJ, Brasil

\begin{abstract}
The present paper is a reassessment of the empirical and theoretical arguments presented by some minimalist accounts for binding. Some of them assume that the binding principles are conditions on LF representations, while others argue that they are derived by narrow syntax computations. I present some observations indicating that there is not yet a satisfactory account for binding. Despite that, the amounted evidence indicates that binding is derivational. Nevertheless, pragmatics seems also engaged in building coreferentiality.

Keywords: Binding Principles; Minimalism; Logical Form; Syntax; Pragmatics
\end{abstract}

\footnotetext{
"Full professor at the Pontifical Catholic University of Rio de Janeiro (PUC-Rio) and a research scholar at CNPq - Brazilian National Council for Scientific and Technological Development. She holds a Bachelor's Degree in Portuguese language and literature from UnB - University of Brasilia, a Master's Degree in Linguistics from UnB, and a Doctoral Degree in Formal Linguistics from University of Maryland, College Park. Her research interests are: (a) psychosis and language impairments; (b) cross-linguistic syntactic studies, with emphasis on less-studied languages, such as sign languages and native languages of south America; (c) formal comparative studies on communication systems within the primate order. Cilene Rodrigues is a member of ABRALIN - Brazilian Linguistics Association, and of SBPC - Brazilian Society for the Advancement of Science. E-mail: crodrigues@puc-rio.br. ORCID: https://orcid.org/0000-0001-5324-7486.
} 


\section{Introduction}

The demolition of the Government and Binding Theory (GB) in favor of a more minimalist, theoretically austere, research program was a necessary step towards explanatory adequacy. However, as a price to be paid, many phenomena well established within GB had to be reexamined. In this paper, we will consider one of them: binding.

Binding theory is a hallmark of the success of Generative Grammar. Principles A, B, and C, coined within the GB framework to account for the distribution of $\mathrm{R}$ (eferential)-expression, pronouns, and anaphors, are a flagship of the descriptive adequacy of the formal apparatus proposed by Generative Grammar. Taken to be part of UG, these principles provided a fairly adequate description of the grammatical system (I-language) internalized by adult native speakers, who allow the interpretative dependencies in (a) but not in (b):

(1) a. John $_{1}$ said that Peter ${ }_{2}$ likes himself

b. ${ }^{\star} J_{0 h n}$ said that Peter ${ }_{2}$ likes himself

(2) a. John ${ }_{1}$ said that Peter ${ }_{2}$ likes him 1

b. ${ }^{*}$ John $_{1}$ said that Peter likes him $_{2}$

(3) a. Even [[John $]_{1}$ 's friends $]_{2}$ like John

b. ${ }^{\star}$ Even John ${ }_{1}$ likes John 1

Once restrictions on occurrences of full nominal expressions and wh-traces, and the syntactic environments of anaphors and pronouns were theoretically formulated (Jackendoff, 1972; Reinhart, 1976), different analyses were proposed to account for the distribution of nominal expressions (see Chomsky, 1976, 1980, 1981, 1982, 1986; Huang, 1983, among others), culminating in the so-called classical binding theory, with the binding principles been stated as follows:

Principle A: An anaphor is bound in its governing category.

Principle B: A pronoun is free in its governing category.

Principle C: A R-expression is free. (Chomsky, 1981, p.188)

Where bound is understood as:

An anaphor $\alpha$ is bound in $\beta$ if there is a category c-commanding it and co-indexed with it in $\beta$; otherwise, $\alpha$ is free in $\beta$. (Chomsky, 1980, p. 10)

And governing category is defined as:

The relevant governing category for an expression $\alpha$ is the least complete functional complex containing a governor or $\alpha$ in which $\alpha$ could satisfy the binding theory with some indexing. (Chomsky, 1986, p. 171) 
The classical binding theory affected the architecture of the GB framework, being at the same time affected by it; it has three features that made it incompatible with the tenets of the Minimalist Program. First, binding was understood within GB as an independent module of the Grammar, not following from any other module or general principle. Second, it was assumed that Grammar could insert non-lexical material (indices) into the structure. Third, structural domains were determined in terms of government.

In order to achieve explanatory adequacy, the minimalist program eliminates all technical machinery that could not be justified in terms of an optimal design of computation (i.e., derivational economy) or in terms of interface requirements (Full Interpretation Principle). Hence, the minimalist program rapidly got rid of all modules proposed within GB.

The computational system is now understood to be a minimal procedure, reduced to recursive applications of Merge, building structures based solely on the content of a numeration. No object can be added during the course of the derivation (Inclusiveness Condition - Chomsky, 1995, p. 228). Therefore, a minimal(ist) Grammar does not assign indices to lexical items to encode interpretative dependencies.

Government is propagated within GB theory as a way of demarcating syntactic domains. However, the Minimalist Program shows that syntactic domains are consequences of an economic criteria applied to operations of the computational system, defining closed derivational cycles. Hence, calling upon the notion of the Governing Category to define the domains in which binding relations take place is not right.

In short, considerations about reducing the Grammar's apparatus to its minimum forced the partition of the binding theory, reevaluating the necessary and theoretical adequacy of each of its components. As a result, the empirical facts in (1)-(3) and the generalizations behind the principles of binding theory are now to be captured in a minimal(ist) fashion. As Reuland (2011, p. 6) puts it, "the classical binding theory is too bad to be true, but too good to be false".

The present paper is a reassessment of the empirical and theoretical arguments presented by some of the main minimalist accounts for binding. The conclusion is that our current formal understanding of binding is incomplete. There is not yet a satisfactory account for this phenomenon. Some ongoing proposals assume that the binding principles follow from conditions on LF representations, others argue that they are derived by computations within narrow syntax. This disagreement is not a novelty. Although, within GB, it was agreed that the binding principles were conditions (or filters) on representations; there was already a discussion about the level of representation in which they applied. Chomsky (1981), while defining Principles A, B and C, placed them at S-structure, but Belletti and Rizzi (1988) presented strong evidence that Principle A could apply at any level (D-structure, S-structure, LF).

The present paper shows, however, that, neither the representational nor the derivational accounts present a fitting explanation for binding, although the available evidence indicates that binding reflects syntactic processes. Yet, in 
order to understand the phenomenon of coreferentiality in its totality, we have to deepen our understanding of the syntax-pragmatics interface.

Before we go on, an important proviso: we concentrate on data from English here, leaving aside issues related to cross-linguistic variation, which would force us to take a whole different approach to the phenomenon under discussion.

The paper is organized as follows. In section 2, we examine analyses in which the binding principles are taken to be conditions on LF representations (Chomsky, 1993; Fox \& Nissenbaum, 2004) or consequences of interface procedures of competition among representations (Schlenker, 2005; Reinhart, 2006). In section 3 , we discuss syntactic analyses that derive binding through syntactic movement (Hornstein, 2000, 2006; Kayne, 2002). Section 4 is dedicated to some conclusions and remarks upon the facts we presently know.

\section{Binding as conditions on LF representations}

\subsection{Binding and reconstruction effects}

Chomsky (1993) and Chomsky and Lasnik (1993) argue that principles A, B, $\mathrm{C}$ are interpretative conditions, defining them as (4)-(6), where $\mathrm{D}$ is understood as a relevant local domain.

(4) If $\alpha$ is an anaphor, interpret it as coreferential with a ccommanding phrase in $\mathrm{D}$.

(5) If $\alpha$ is a pronoun, interpret it as disjoint from every ccommanding phrase in $\mathrm{D}$.

(6) If $\alpha$ is a $R$-expression, interpret it as disjoint from every ccommanding phrase.

(Chomsky, 1993, p. 211)

It is assumed that these principles apply as a block to LF representations. Chomsky's (1993) arguments for adopting this position are based on reconstruction effects. Building on the copy theory of movement, his analysis takes the contrast in ((7) - Chomsky, 1993, p. 2004) to be consequence of reconstruction at LF. It follows Lebeaux's (1998) conclusion that complements must be inserted into the derivation cyclically, while adjunction can be inserted noncyclically. In (7a), where the bracketed clause is a complement, a copy of John must be present within the lower copy of the wh-phrase. In (7b), the bracketed clause, being an adjunct (a relative clause), might have entered the derivation after movement of the wh-phrase. Thus in (7b), in contrast with (7a), the lower copy of the wh-phrase may not contain a copy of John. Thus, if A-bar movement triggers reconstruction at LF, in (7a), but not in (7b), coreference between he and John leads to a Principle C violation. 
(7) a. Which claim [that John was asleep] was he ${ }_{1}$ willing to discuss which claim [that John was sleep]

b. Which claim [that John was asleep] was he willing to discuss which claim

In ((8) - Chomsky, 1993, p. 2004), as A-movement is not subject to reconstruction at LF, only the upper copy of the wh-phrase feeds interpretation. Since there is no c-command relation between him and John, there is no violation of Principle C. That is, John is not bound by the pronoun, although accidental coreference (i.e., coreference without binding) might happen.

(8) [The claim that John was sleep] seems to him [the claim that John was sleep] to be correct

A similar line of reasoning is applied to Principle A. ((9) - Chomsky, 1993, p. 2007) is ambiguous due to an interaction between Principle A and an idiomatic interpretation of the lower VP. The VP took picture in (9) can receive either an idiomatic (meaning photographed) or a non-idiomatic reading, but the idiomatic reading is in function with the interpretation of himself as Bill: the VP is an idiom only if Bill is the antecedent of himself.

(9) John wondered [[which picture of himself] [Bill took [which picture of himself]]]

Given that A-bar movement forms an operator-variable structure, (9) can have two logical forms: (10a), in which the operator and the variable (i.e., the whole wh-phrase) are interpreted in their spell-out position, and (10b), where the operator (which $x$ ) is interpreted in this spell-out position, but the variable ( $x$ is picture of himself) is interpreted within the lower occurrence of the wh-phrase. In obedience to Principle A, if (10a) is selected for interpretative purposes, John is the antecedent of himself; if (10b) is selected, Bill is antecedent. Given that take picture is an idiom only if its parts form a unit at LF, only (10b) is compatible with an idiomatic interpretation of took picture.

(10) a. LF1: John wondered [[which $x, x$ a picture of himself] [Bill took $x]$ ]

b. LF2: John wondered [[which $x$,] [Bill took [ $x$ a picture of himself]]

As Chomsky noticed, this analysis leads to a tension. In (11a), given that John and Bill can be both antecedents of the anaphor, reconstruction inside the lower VP has to be an option. However, in order to prevent violation of Principle B (11b) and violation of Principle C (11c), reconstruction has to be blocked. [Data from Chomsky, 1993, p. 2005] 
(11) a. John wondered which picture of himself Bill saw

b. John wondered which picture of him Bill saw

c. John wondered which picture of Bill he saw

To deal with this, Chomsky proposes an LF-movement approach to anaphors, suggesting that these elements cliticize into the closest predicate at LF, as in (12). In cases involving movement with pied-piping of the anaphor, like in (9), cliticization targets either the lower (13a) or the higher (13b) copy of the anaphor. Thus, (13a) is compatible with the logical form in (10a), whereas (13b) is compatible with the (10b).

John took self $_{\text {picture of himself] }}$

(13) a. John wondered ${ }_{\text {self }}[$ which picture of himself] [Bill saw [which picture of himself]]]

b. John wondered [[which picture of himself] [Bill saw $_{\text {self }}[$ which picture of himself]]]

Therefore, Chomsky distinguishes anaphors from pronouns and R-expressions by considering that only anaphors involve cliticization at LF. Reconstruction is obligatory only if an anaphor within the moved constituent cliticizes into a lower predicate. In structures involving pronouns and R-expressions, cliticization does not happen and nothing really forces reconstruction; consequently, Principle B and $\mathrm{C}$ violations are avoided.

Chomsky (1993) was mainly concerned with showing that S-structure is not necessary to accommodate binding. His arguments centered on evidence showing that binding could (emphasis on could) be placed at the LF interface. As he observed, the arguments he provides for assuming binding to be conditions on LF representations are weak. They are compatible with the analysis proposed, but they seem equally compatible with a derivational approach of binding. Assuming the copy theory of movement (Chomsky, 1995), there is no uncontested evidence that binding must apply after reconstruction. In effect, the assumption that anaphors involve LF movement empties the argument for reconstruction. The reconstruction effects observed above can be captured independently of reconstruction: himself in (7) is interpreted as coindexed with Bill if the anaphors cliticize into the lower predicate, prior to wh-movement (assuming binding to be resolved within narrow syntax). If the anaphor cliticizes into the upper predicate, after wh-movement, John is the antecedent. In (7b), violation of Principle $\mathrm{C}$ prevents the wh-variable within the predicate from being interpreted, as Chomsky himself suggested.

Chomsky's proposal faces some other technical difficulties. As pointed by Heinat (2006) and Hicks (2009), although the binding principles in (4)-(6) do not make reference to indices and government, new terms are used without technical definitions. How are relevant binding domains for anaphors and pronouns 
demarked? What are the grammatical mechanics that bring about coreference and disjoint reference dependencies if indices are not available? Finally, it is to be noticed that Chomsky's (1993) approach does not eliminate binding as a module (Hicks, 2009). The principles in (4)-(6) do not follow from any general principle of Grammar nor from bare output conditions, rather they are presented as encapsulated, self-supporting conditions on representations.

Fox and Nissenbaum (2004) provide additional evidence for assuming that Principle A applies to LF representations, and their arguments are also based on reconstruction. Their first piece of evidence involves creation VPs, which, similarly to the idiomatic reading of take picture, force LF reconstruction in cases of A-bar movement, as first observed by Heycock (1995). ((14) - Fox \& Nissenbaum, 2004, p. 478) can have only (15a) as its logical form. (15b), in which the whole wh-phrase is interpreted in its surface position, is not compatible with the semantic properties of the lower VP, which is a creation VP - have ideas.

(14) How many ideas is John likely to have?

(15) a. LF1: What is the number $n$ such that John is likely to have $n$ ideas

b. LF2: \#What is the number $n$ such that there are ideas and John is likely to have those ideas?

The contrast in ((16) - Fox \& Nissenbaum, 2004, p. 479), thus, follows. (NB: have ideas is a creation VP, hear about ideas is not.)

(16) a. I asked John how many ideas about himself Mary is likely to hear about $/{ }^{*}$ have

b. I asked John how many ideas about him Mary is likely to hear about/have

In a comparable manner, in ((17) - Fox \& Nissenbaum, 2004, p. 480), himself cannot co-occur with the expletive there, which forces reconstruction (Heim, 1998; Frampton, 1991). To satisfy Principle A in (17), reconstruction cannot take place, but, at the same time, reconstruction must occur to license there.

(17) I asked John how many books about himself Mary thinks ( ${ }^{*}$ there) are in the library

Additional evidence is in ((18) - Fox \& Nissenbaum, 2004, p. 481). A combination of himself and a bound variable reading of her yields the interpretive conflict in (18a): the bound variable reading of her is possible only if the lower copy of the wh-phrase is accessed, but satisfaction of Principle A requires the higher copy of the wh-phrase to be interpreted. In (18b), bound variable reading is not at stake, thus, the anaphor can be properly licensed. 
His aides should have explained to Bill Clinton ${ }_{1} \ldots$

a. [what kinds of pictures of ${ }^{\star}$ himself $_{1}$ and her ${ }_{2}$ baby] no mother wants to see

b. [what kinds of pictures himself ${ }_{1}$ and her ${ }_{2}$ baby] Mrs. Jones wants to see

The examples in ((19) - Fox \& Nissenbaum, 2004, p. 481) are possible pieces of evidence against interactions between reconstruction and Principle A. The verb compose, being a creation verb, forces reconstruction of the wh-phrase; however, the reciprocal expression each other (subject to principle A) can be licensed only if the upper copy of the wh-phrase is interpreted.

(19) a. How many songs about each other did John and Mary say Bill should compose?

b. John and Mary wonder how many songs about each other Bill should compose.

The authors factor (19) out by analyzing each other in (19) as a logophor, licensed through discourse conditions, which require the antecedent of the logophor to be salient (e.g., the entity whose point of view is being reported, the source of information). The authors assume that subjects of predicates headed by bridge verbs are discourse salient. Hence, in (19), the subject of the main sentence, John and Mary, is salient and, as such, it serves as the referent of the logophor each other.

Fox and Nissenbaum's arguments do not fare better than those presented in Chomsky (1993). They do not prove that reconstruction is a sine qua non condition for satisfaction of Principle A. Approaches in which Principle A is met derivationally (see section 3 ) make the same predictions as Fox and Nissenbaum. In addition, Uchiumi (2006) and Hicks (2009) pointed out that native speakers' judgments for the interactions presented by Fox and Nissenbaum can be fuzzy.

\subsection{Binding as a consequence of pragmatic principles}

Schlenker (2005) concentrates on Principle C, suggesting that it follows from a Gricean maxim of minimization - which he takes to express itself as the pragmatic Principle of Minimalize restrictors!

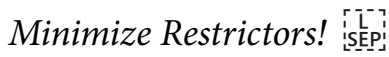

A definite description the $A B$ [where the order of $A$ vs. $B$ is irrelevant] is deviant if $A$ is redundant, i.e. if: i[s]

(i) the $B$ is grammatical and has the same denotation as the $A$ (= Referential Irrelevance), and istepi

(ii) A does not serve another purpose (= Pragmatic Irrelevance)

(Schlenker, 2005, p. 391) 
To see Minimize Restrictor! in action, consider the examples in (20). If we hold the presupposition that there is only one American president at the moment, blond in (20a) is unnecessary for building the denotation of the nominal expression; and, since it also has no pragmatic effect, its presence violates Minimize Restrictors!, causing (20a) to be deviant. In contrast, stupid in (20b) is natural because it adds a pragmatic effect, expressing the speaker's attitude towards the referent of the nominal expression.

(20) a. The blond American president

b. The stupid American president

To understand how Schlenker uses Minimize Restrictor! to explain Principle C, let us start with the data in ((21) - Schlenker, 2005, p. 386), which demonstrate that Principle $\mathrm{C}$ violations arise whenever a R-expression is bound (i.e., share its index with a c-commanding antecedent). Violations of Principle $\mathrm{C}$ are more severe if the R-expression is bound by a pronoun, as in (21b).

(21) a. ?? John $n_{1}$ loves people who admire John

b. ${ }^{\star} \mathrm{He}_{1}$ loves people who admire John

c. John ${ }_{1}$ 's mother loves people who admire John

d. His ${ }_{1}$ mother loves people who admire John ${ }_{1}$

However, epithets, which are full DPs, do not cause Principle C violations. [Data from Schlenker, 2005, p. 386]

(22) a. $\mathrm{John}_{1} /$ ? $\mathrm{He}_{1}$ is so careless that [the idiot] $]_{1}$ will get killed in an accident one of these days

b. [Pope John Paul II] $]_{1}$ was so beloved that the entire world is now mourning [the great man $]_{1}$

Schlenker (2005, p. 387) also provides the contrast in (23) and (24), in which (23) obviates Principle C, but (24) does not.

(23) [A linguist working on Binding Theory $]_{1}$ was so devoid of any moral sense that he ${ }_{1}$ forced [a physicist working on particles] to $\mathrm{h}$ i r e

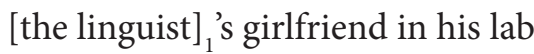

(24) ${ }^{*}$ [A linguist working on Binding Theory $]_{1}$ was so devoid of any moral sense that he ${ }_{1}$ forced me to hire [the linguist] ${ }_{1}$ 's girlfriend in his lab

The author suggests that part (i) of Minimalize Restrictors! (i.e., A could be dropped without affecting the denotation of the description) explains standard cases of Principle C violation (21), while part (ii) (i.e., A does not have any pragmatic effects) accounts for Principle C exceptions ((22) and (23)). Pronouns 
are taken to be very short descriptions, being proxies for full DPs. Thus, Minimalize restrictors! forces a preference for pronouns over full DPs, unless a full DP is required for semantic or pragmatic reasons. Minimalize Restrictors! can, thus, be seen as a judge in a competition between full DPs and pronouns. (21a) and (21b) are, therefore, filtered out because there is no pragmatic or semantic reason for an occurrence of John in the object position of admire. In both sentences, this occurrence can be substituted by a pronoun with no loss of semantic information. Contrarily, the epithets in (22) cannot be substituted by pronouns because pronouns do not have the pragmatic effect/load that epithets have. In (23), unlike (24), the linguist, within the possessive DP (the linguist's girlfriend), is licensed because it serves as a disambiguator. There are two possible antecedents for the possessor description, a linguist working on Binding Theory and a physicist working on particles. Substituting a linguist by his would cause ambiguity. Ambiguity is not at stake in (24); consequently, a pronoun, but not full $\mathrm{DP}$, is licensed within the possessive phrase.

In Schlenker's account, the c-command restriction on Principle $\mathrm{C}$ is modeled as a pragmatic constraint on discourse-prominence: a nominal expression referring back to a super salient antecedent must minimalize its restrictor. However, as Johnson (2012) correctly points out, the c-command restriction on Principle $\mathrm{C}$ cannot be fully subsumed under the notion of discourse-prominence. Principle $\mathrm{C}$ violations are more severe than deviances caused by disobedience to discourse-prominence constraints. Take ((25) - Johnson, 2012, p. 164) as an example. According to Schlenker, a full DP causes deviance (25i), whereas a pronoun does not (25ii). Schlenker explains that the antecedent given in the context is super-salient and the DP in (25i) is not adding any extra semantic or pragmatic effect. However, as observed by Johnson (2012), (25i) is not severely deviant as (21a) and (21b) are. Also, in (25), violation of Minimize Restrictors! can be mitigated in ways that violations of Principle C cannot. Consider ((26) - Johnson, 2012, p. 164) as an example. (26i), for instance, seems to be fully acceptable. In contrast, using a proper name to refer back to an R-expression does not alleviate Principle C effects, as shown in ((27) - Johnson, 2012, p. 164).

(25) Context: A professor and her Teaching Assistant are grading a late exam together. After both of them have looked at some length at the exam, the professor says:

i. ? The student should pass

ii. He should pass

(26) Context: A professor and her Teaching Assistant are grading a late exam together. After both of them have looked at some length at the exam, the professor says: 
i. Tom should pass

ii. He should pass

(27)

${ }^{*}$ The woman $_{1}$ said that I liked Nancy

The idea that correference is regulated by pragmatic conditions is an old one. In Reinhart (1983), it was suggested that coreferentiality abides to a pragmatic principle that forces binding over accidental coreference. This principle, named Rule I by Grodzinsky and Reinhart (1993, p. 79), is defined as follow:

\section{Rule 1 - Intrasentential coreference}

NP A cannot corefer with NP B if replacing A with C, a variable anaphorically bound by $\mathrm{B}$, yields an indistinguishable interpretation.

Rule 1 states that, whenever a binding relation is possible, it will apply, blocking accidental coreferences. This preference for binding is due to the fact that binding, differently from accidental coreference, yields semantic representations in which the element's denotation is fixed unambiguously. Reinhart (1983) and Grodzinsky and Reinhart (1993) observe that Rule 1 cannot be syntactic, as it involves knowledge of grammar, meaning and appropriateness of context. Hence, Rule 1 applies at LF.

Chien and Wexler (1990) present experimental evidence that acquisition of principle $\mathrm{C}$ involves maturation of principles.

Reinhart (2006) takes a similar, but yet different approach, suggesting that binding is resolved at LF via a reference-set computation process that compares pairs of representations. Once a derivation reaches the interface, a comparable representation (i.e., a representation built upon the same numeration) is built and compared to that other. If both have the same logical form, then the most economical is selected, blocking the non-economical one. This reference-set computation is taken to be a repair mechanism activated whenever there is an imperfection in the representation. It applies to binding as follows: binding is assumed to be more economic than covaluation (i.e., accidental coreference) in terms of semantic processing, as the system tries to resolve a free variable as soon as possible (least effort view of economy). Consider ((28) - Reinhart, 2006, p. 165). The logical form of (28) is (29a), in which the pronoun is not bound by the $\lambda$-operator, remaining as a free variable until it gets its value from the discourse referent's storage, which includes Lili. (29a) has, thus, an imperfection, a free variable. Consequently, the reference-set computation process is activated, building the logical form in (29b), where the pronoun is bound by the $\lambda$-operator. Since there are no semantic differences between (29a) and (29b), (29b) is selected as the optimal representation.

(28) Lili thinks she's gotten the flu 
(29)
a. LF1 (Covaluation):
Lili $(\lambda \mathrm{x}$ ( $\mathrm{x}$ thinks $\mathrm{z}$ has gotten the flu)
$\& \mathrm{Z}=$ Lili $)$
b. LF2 (Binding):
Lili $(\lambda \mathrm{x}$ ( $\mathrm{x}$ thinks $\mathrm{x}$ has gotten the flu)

Consider ((30) - Reinhart, 2006, p. 180) now. LF1 (31a) is costly as it contains a free variable; thus, LF2 (31b) is built for comparative reasons. However, the comparison is canceled because these two LFs are not semantically comparable, as they have different meanings. ((31a) means that only Lucie shows husbandrespect; (31b) means that only Lucie shows respect for Lucie's husband.)

(30) Only Lucie respects her husband

(31) LF1: Only Lucie ( $(\lambda \mathrm{x}$ ( $\mathrm{x}$ respect $\mathrm{x}$ 's husband)

LF2: Only Lucie $((\lambda \mathrm{x}$ ( $\mathrm{x}$ respect her husband) $\&$ her $=$ Lucie

This approach requires a redundancy of application of economic criteria. Principles of economy apply at syntax. They regulate syntactic operations, imposing restrictions on their applications (Movement and locality, for example). A reference-set computation requires reapplication of principles of economy at the interface, taking semantic processing into consideration. Firstly, it is unclear how processing fits into this account. Is reference-set computation supposed to apply on production? Also, how is a representation assembled at the interface for comparative purposes? That is, if an LF is the representation of a syntactic derivation, how can one be constructed at the interface? Note that a logical form involving binding is built whenever a representation has covaluation (i.e., whenever a pronoun reaches the interface as a free variable), not the other way around. Thus, it seems to me that, to execute Reinhart's proposal, one needs to assume that the representation that requires most syntactic operations (binding) is the one that is built at the interface for comparative purposes.

\section{Binding as a result of narrow syntax computations}

There are two types of analyses that take binding to be the result of syntactic processes: Moved-based and Agree-based analyses. Due to space and time reasons, I will focus on Moved-based analyses in this paper. See Heinat (2006), Hicks (2009), Reuland (2011) and Johnson (2012) for developments of Agreebased approaches.

\subsection{Pronouns and anaphors as grammatical formatives}

Hornstein $(2000,2006)$ aims at eliminating Principles A and B of the Binding Theory from UG, using the theory of movement. Rescuing Lees and Klima's (1963) idea that anaphors and pronouns are both generated within the transformational component of Grammar, Hornstein claims anaphors and bound pronouns 
are both formed by the computational system of grammar, rather than being elements stored in the lexicon. In his proposal, anaphors involve A-movement plus pronominalization at PF. A sentence like (32 - Hornstein, 2000, p. 159), for instance, is derived as shown in (33). The DP John is first merged with self, a Case bearer, but semantically inert morpheme. The complex thus formed merges with the verb, and John gets the internal theta-role assigned by the verb (33a). After that, John moves to spec of $v \mathrm{P}$, receiving the external theta-role (33b), and then to spec of TP, valuing its Case feature as nominative (33c). The morpheme self value its Case as accusative within the $v \mathrm{P}$ shell. At $\mathrm{PF}$, in order to guarantee linearization, chain reduction (Nunes, 1995) applies deleting the lower copy of John. However, being a bound morpheme, self cannot stand-alone, and a process of pronominalization kicks in at $\mathrm{PF}$, inserting the pronoun him to give morphophonological support to self (33c).

(32) John likes himself

(33) a. [ ${ }_{\mathrm{VP}}$ like [[John]self]]

b. $\left[_{\mathrm{TP}} \operatorname{John}\left[\mathrm{T}\left[_{v \mathrm{P}}\right.\right.\right.$ John $\left[v\left[_{\mathrm{VP}}\right.\right.$ like [[John]self $\left.\left.\left.\left.\left.]\right]\right]\right]\right]\right]$

c. $\left[_{\mathrm{TP}} \operatorname{John}\left[\mathrm{T}\left[_{\nu \mathrm{P}} \operatorname{John}[v\right.\right.\right.$ [like [[fohn] self $\left.\left.\left.\left.\left.]\right]\right]\right]\right]\right]$

d. $\left[_{\mathrm{TP}}\right.$ John [T $\left[_{v \mathrm{P}}\right.$ John [ $v\left[_{\mathrm{VP}}\right.$ John [like [him]self $\left.\left.\left.\left.\left.]\right]\right]\right]\right]\right]$

As for bound pronouns, it is proposed that these elements are inserted by the computational system whenever movement fails to apply. They are, thus, proxies for variables that could have been created via movement. For concreteness, consider the example in ((34) - Hornstein, 2000, p. 176). First, the quantifier everyone merges with the possessive noun mother, and the DP thus formed enters the derivation as the direct object (35a), after that everyone moves to spec of $v \mathrm{P}$ (35b) to get the external theta-role and to spec of TP to value its Case feature (35c).

(34) Everyone ${ }_{1}$ loves his ${ }_{1}$ mother

(35) a. [ ${ }_{\mathrm{VP}}$ love [everyone's mother] $]$

b. $\left[_{V \mathrm{P}}\right.$ everyone $\left[v\left[_{\mathrm{VP}}\right.\right.$ love [everyone's mother] $\left.\left.]\right]\right]$

c. ${ }^{*}\left[_{\mathrm{TP}}\right.$ everyone $\left[\mathrm{T}\left[_{\mathrm{vP}}\right.\right.$ everyone $\left[v\left[_{\mathrm{VP}}\right.\right.$ loves [everyone's mother]]]]]]

The derivation in (35) is not convergent because movement of everyone from inside the possessive DP (everyone's mother) violates the Left Branch Condition (Chomsky, 1995, p. 263). Thus, in order to rescue the derivation, Pronominalization takes place, replacing the lower copy of everyone by the pronoun his.

$\left[_{\mathrm{TP}}\right.$ everyone $\left[\mathrm{T}\left[_{\mathrm{vP}}\right.\right.$ everyone $\left[v\left[_{\mathrm{VP}}\right.\right.$ loves [ his mother $\left.\left.\left.\left.\left.]\right]\right]\right]\right]\right]$ 
(36) is, in this account, a convergent alternative to the non-convergent derivation in (35).

Hornstein constrains pronominalization by assuming that it is a costly operation that applies as a last resort strategy to repair a structure that would fail convergence otherwise. Thus, a derivation with pronominalization happens only if required for convergence.

Hornstein does not assume that all pronouns are grammatical formatives. Only bound pronouns are. As generally assumed, deictic pronouns are lexical elements that may corefer accidently with an intrasentential nominal expression. Fiengo and Higginbotham (1981) observed that, contrary to deictic pronouns, bound pronouns are phonologically reduced, non-stressed forms (37). Hornstein takes this phonological difference to be related to the proposed grammatical/ lexical distinction.

(37) John read that book about 'im

The idea that pronouns are a last resort strategy has been particularly motivated by the lack of interaction between pronouns and island effects. Chomsky (1981), for example, suggests that in ((38) - Italian - Chomsky, 1981, p. 240), the subject of the most embedded clause is a based generated resumptive null pronoun (pro). Given that movement in (38) is blocked by subjacency, base generation of a pronoun is a necessary derivational step in (38):

(38) Ecco la regazza [che mi domando [chi credi que pro possa VP]] here the girl who myself ask who thinks that may VP

'This is the girl that I wonder who thinks that she may VP'

Shlonsky (1992), analyzing restrictive relative clauses in Hebrew and Palestinian Arabic, provides additional arguments for assuming pronouns to be last resort elements. He argues that these elements occur every time movement is blocked. Within Hebrew relative clauses, pronouns are obligatory in indirect object positions with no preposition pied-piping ((39a) - Hebrew is not a P-stranding language) and within possessive DPs (39b). [Data from Shlonsky, 1992, p. 445]

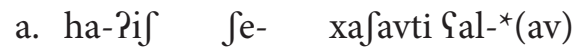
the-man that (I) thought about-(him) 'The man that thought about'

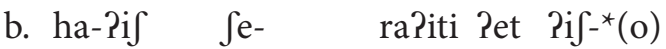
the-man that- (I) saw ACC wife-(his)

'The man whose wife I saw'

Nevertheless, pronouns are in free variations with gaps formed by movement in direct object ((40a) - Shlonsky, 1992, p. 444) and embedded subject positions 
((40b) - Shlonsky, 1992, p. 450). Also, gaps, but not pronouns, are accepted in the subject position of the highest clauses within the relative clause domain (41).

a. ha-Pis Se- ra?iti (?oto)

the-man that (I) saw (him)

"The man that I saw"

b. ha-Pif Se- xafavt $\int \mathrm{e}-(\mathrm{hu})$ melamed Sanglit

the-man that (you.F) thought that-(he) teaches English

'The man that you thought he teaches English'

(41) ha?if $\int \mathrm{e}-\left({ }^{*} \mathrm{hu}\right)$ Pohev ?et Rina

the-man that-(he) loves ACC Rina

'The man who loves Rina'

Schlonsky argues that the free variation in (40) is illusory, being an effect of Hebrew having two morphological identical, but syntactically distinct, relative clause complementizers $\left(\int \mathrm{e}\right)$. While the first one $\left(\int \mathrm{e}_{\mathrm{A}}\right)$ projects an A-specifier, the second on $\left(\int \mathrm{e}_{\mathrm{A}^{\prime}}\right)$ projects an A-bar specifier. The gapped versions of the relative clauses in (40) contains $\int \mathrm{e}_{\mathrm{A}^{\mathrm{A}}}$, allowing A-bar movement to spec of $\mathrm{CP}$ crossing over the subject position, which is a A-position (A-bar movement over an A-position). Conversely, occurrences of resumptive pronouns indicate that $\int \mathrm{e}_{\mathrm{A}}$ was selected and, consequently, movement to spec of CP (an A-position) crossing over the subject, violates Minimal Link Condition (A-movement over an A-position). Thus, in $\int \mathrm{e}_{\mathrm{A}}$ relative clauses, convergence depends upon a resumption strategy. In (41), since the Minimal Link Condition is not at play (movement to spec CP does not cross over any position), it does not matter which complementizer is selected, movement takes place, and the resumption strategy is not invoked for economic reasons.

Although this is an interesting idea, it also faces some difficulties. First, consider resumptive pronouns in Lebanese Arabic, which are taken to be last resort elements in Aoun's (2000) analysis of definite and indefinite restrictive relative clauses, where the terms definite and indefinite make reference to the definiteness feature of the relativized DP. In both relative clauses, resumptive pronouns (realized as a clitic) obligatorily occur in all non-subject positions. However, these two types of relative clauses differ in complementizer selection: while the definite relative clauses contain the definite complementizer yalli, indefinite relative clauses have no overt complementizer. Also, although island effects are obviated in definite and indefinite relative clauses, reconstruction effects are observable in and only in definite relative clauses. As shown in (42 - Aoun, 2000, p. 20), a resumptive pronoun within a definite relative clause can be bound by a quantified expression, receiving a bound variable reading, indicating that the relativized DP is interpreted from the pronoun's position (reconstruction): 
$(42)$

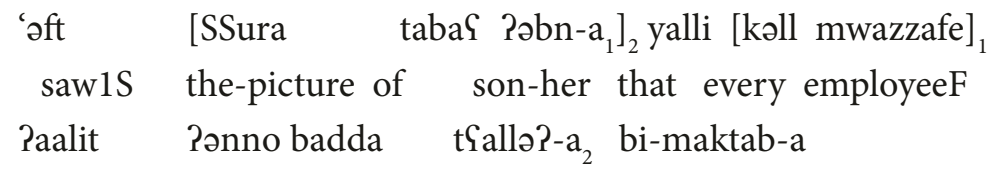

said3SF that want3SF hand3SF-it in-office-her

'I saw the picture of her son that every employee said she wants to hang in her office'

Assuming reconstruction to be tied to movement, Aoun proposes that all definite relative clauses involve resumption, the pronoun being either overt or null. Gapped relatives are not derived via movement of the relativized DP, but via insertion of a resumptive null pronoun. At LF, the null pronoun moves to spec-CP to check the formal features of the complementizer yalli (definiteness and $\varphi$-features).

$$
\begin{gathered}
{\left[\mathrm{DP}_{1}\left[\mathrm{CP}\left[\text { Pron }_{1} \text { yalli }\right]\left[\ldots \text { Pron }_{1}\right]\right]\right]} \\
\uparrow \ldots \ldots \ldots \ldots \ldots
\end{gathered}
$$

Indefinite relative clauses have no complementizer, and, consequently, this covert movement does not apply, and reconstruction effects are not observed.

The reconstruction effects observed would be elegantly captured by a raising analysis, along the lines proposed by Kayne (1994). However, Aoun argues against raising, suggesting instead that generation of definite relative clauses involves covert movement of a pronoun plus a coindexation process that creates an extended LF chain, containing the relativized DP and the occurrences of the pronoun in Spec-CP and in situ. This is a complicated way of capturing reconstruction effects. It hinges on assignment of indices and on a covert movement that is not independently motivated. Aoun argues that a raising analysis is not feasible because it does not explain the presence of resumptive pronouns. There is a loophole in this reasoning: the analysis proposed is intended to explain resumptive pronouns. Hence, resumptive pronouns cannot be an argument to justify the analysis itself.

It seems to me, then, that in order to maintain the idea that resumptive pronouns are last resort items, Aoun (2000) adopts a non-straightforward and not well-motivated analysis for restrictive relative clauses.

Similar island amelioration effects have been reported for English. Asudeh (2004, p. 320), for instance, reports that (44a) sounds better than (44b).

(44) a. I'd like to meet the linguist that Peter knows a psychologist that works for her

b. I'd like to meet the linguist that Peter knows a psychologist that works for

This intuition, however, is not securely confirmed by experimental results. For instance, Heestand et al. (2011), in an acceptability judgment task with use 
of a Likert scale, and in a speeded presentation task imposing a time pressure on participants, tested the acceptability of resumptive pronouns and gaps within restrictive relatives and VP adjunct clauses in English. The results indicate no significant difference between gaps and pronouns. Heestand's et al. experiments were replicated in Polinksy at al. (2013) using auditory stimuli. The results obtained were basically the same as those reported by Heestand's et al. Also, Beltrama and Xiang (2016) designed a series of three experiments in English (two comprehensibility tasks with and without a given context, and one acceptability task) to verify acceptability contrasts between gaps and pronouns in relative clauses with one or two levels of embedding. The results indicate that resumptive pronouns, as opposed to gaps, obviate island effects. However, a significant difference was found only in the comprehensibility task with a given context. This led the authors to conclude that resumptive pronouns act as rescuers not at the grammatical level, but at processing. Therefore, all at once, these results do not favor the last resort analyses presented above, which posit pronoun insertion as a grammatical intervention to avoid non-convergence.

Let me add to this the fact that there are contexts in which pronouns and gaps seem to be in real free variation. Consider, for instance, parasitic gap sentences as (45). There is no report on the literature that a pronoun is blocked or ill-favored in object position inside adjunct clauses.

(45) a. Which article did you file without reading?

b. Which article did you file without reading it?

Given that parasitic gaps (45a) are taken to be formed via movement (operator-movement (Chomsky, 1986; Nissenbaum, 2000), sideward movement (Nunes, 1995)), a contrast in acceptability between (45a) and (45b) is expected under Hornstein's analysis, where bound pronouns are assumed to be licensed only if movement cannot apply. Thus, (45a) should block (45b), but this does not occur, as the gap and pronoun seem to be equally acceptable. Note that the pronoun in this context behaves as a bound pronoun being amenable to phonological reduction.

(46) Which senator did you vote for without really know 'im?

A further problem involves sentences like (47), in which an anaphor occurs within a conjoined nominal expression. If anaphors occur in cases of nonproblematic movement, while pronouns are inserted in cases of problematic movement, then in (47), the first member of conjoined DP should be a pronoun, not an anaphor, as movement out of a coordinated structure is not allowed (The coordinated structure constraint - Ross (1967)). 
In addition, let me point out, as Safir (2008) and Hicks (2009) did, that taking pronouns to be grammatical formatives incur in violation of the Inclusiveness Condition. Also, Hornstein's implementation of the last resort strategy requires a countercyclical computation. Let us reexamine the derivation in (35)-(36). In (35b), movement of everyone takes place, violating the Left branch Condition. To repair this violation, the computational system tampers with the structure just formed, replacing the lower copy of everyone with a pronoun.

As a clarification note, allow me to point out that within the Minimalist Program the expression last resort strategy has been defined in more than one way. Chomsky $(1991,1995)$, for instance, defines last resort strategies as language-particular rules that apply whenever more general, UG Principles are not possible. This definition is in tandem with Chomsky's (1981) observation that null pronouns (see example (38) above) can act as resumptive elements in null subject languages, being based generated within islands. Hornstein does not seem to conceive last resort strategy in the same way. He models the last resort strategy as a general feature of Grammar.

\subsection{Binding as a reflex of antecedent-pronoun doubling}

Kayne (2002) shares with Hornstein the idea that binding is resolved within narrow syntax, reflecting grammatical computations, movement in particular. However, Kayne's analysis is substantially different from Hornstein's. First, Kayne argues that principle B is not a side effect of Principle A. Hornstein assumes that anaphors (Principle A) are regularly derived by movement, whereas pronouns (Principle B) emerge whenever movement is not possible. Kayne argues against this based on cases like ((48) - Kayne, 2002, p. 144), where pronouns and anaphors are both disallowed.

(48) a. ?We consider me intelligent

b. ${ }^{\star}$ We consider myself intelligent

Kayne also assumes, differently from Hornstein, that bound and deictic pronouns have an equal status, being both lexical items. That is, Kayne tries to reduce pronouns in general to movement.

Also, Kayne's syntactic analysis is based on the desire of unifying cliticdoubling constructions ((49) - French - Kayne, 2002, p. 134) and pronoun/ anaphor-antecedent coreferentiality. ${ }^{1}$

(49) Cela est il vrai?

that is it true

'Is that true?'

Following Kayne (1972) and Uriagereka (1995), Kayne (2002, p. 134) analyze clitic doubling as in (50): 
(50) a. [cela il] est vrai $\rightarrow$ The clitic and its double are merged together

b. est ${ }_{1}$ [ cela il] $\mathrm{t}_{1}$ vrai $\rightarrow$ Verb movement

c. cela est $_{1}\left[\mathrm{t}_{2} \mathrm{il}\right] \mathrm{t}_{1}$ vrai $\rightarrow$ A-bar movement of the double

This analysis is generalized to all cases of pronoun-antecedent coreferentiality, and a sentence like ((51) - Kayne, 2002, p. 143) has the derivation in (52), where the pronoun and its double moves together to an intermediate position before John scoots out, moving to the external argument position within the matrix predicate (52b).

(51) John thinks he $_{1}$ is smart

(52) a. [Thinks $\left[_{\mathrm{XP}}[[\right.$ John he] is smart $\left.]]\right]$

b. [Thinks $\left[_{\mathrm{XP}}[\text { John he }]_{1}\left[\mathrm{t}_{1}\right.\right.$ is smart $\left.\left.]\right]\right]$

c. [John ${ }_{2}$ think $\left[_{\mathrm{XP}}\left[\mathrm{t}_{2} \text { he }\right]_{1}\left[\mathrm{t}_{1}\right.\right.$ is smart $\left.\left.]\right]\right]$

Assuming Phase Impenetrability Condition (Chomsky, 2001), Kayne proposes that inside the constituent [John he], John occupies a spec position, while he is a simple head that might exhaust the rest of the structure. Although Kayne is not clear about the inner structure of this constituent, he assumes that it is a phase and consequently John, in spec position, is available for extraction, while he is not, being spelled out inside the constituent, prior to application of Move in (52c). This blocks the derivation sentences like (53 - Kayne, 2002, p. 137) that violates condition $\mathrm{C}$.

(53) ${ }^{\star} \mathrm{He}_{1}$ thinks John ${ }_{1}$ is smart

Kayne takes the movement analysis to its extremes, arguing that all instances of pronominal coreference (bound and accidental coreference) result from movement. In cases of intersentential coreferentiality ((54), for example, - Kayne, 2002, pp. 138-139), it is suggested that the two sentences form a single complex sentence, akin to a coordinated structure (54b).

(54) a. John $n_{1}$ is famous. $\mathrm{He}_{1}$ is smart, too

b. John ${ }_{1}$ is famous, and he is smart too

This proposal has problems. First, it is claimed that, within the constituent [John he], John does not receive the theta-role assigned to he. Kayne bans derivations in which the same arguments receive two theta-roles. But if John does not receive the same theta-role as he, how are John and he interpreted as being coreferential? The fact that they form a single constituent is not enough to explain coreferentiality. Second, to explain why (55) is ungrammatical, the movement to an intermediate position in (55b) was proposed. This intermediate position is 
assumed to be missing in (55). The nature of this position is unclear. Why can't it be [spec of $v \mathrm{P}$ ] in (55)? Kayne does not discuss any of these issues.

(55) ${ }^{\star} \mathrm{John}_{1}$ consider him intelligent

Also, no detailed discussion is present on how accidental coreferential readings are to be derived from pronoun-antecedent doubling plus movement. Long distance coreferentiality, including intersentential cases like (54), are very hard, if not impossible, to be captured by movement. In (56), for example, moving John over the embedded subject would violate the Minimal Link Condition. As for (54), there is no well-developed theory of movement designed to capture dependencies across sentences. In addition, any attempt to derive the pronoun in (57) from movement would have to presuppose that movement into non c-commanding positions, where the head of the chain formed by the purported movement is in a non c-command position. $)^{2}$

(56) John says that Peter hates him

(57) John's father loves him

A fourth potential problem for Kayne's proposal is actually application of Phase Impenetrability Condition. Cases in which the bound pronoun is part of a possessive DP are particularly difficult to be derived à la Kayne. In (58a), John starts the derivation in spec of the constituent formed by his, which, in its turn, is inside the possessive DP, arguably in a spec position. Hence, when the possessive DP is shipped off to the interfaces, John is shipped together, as part of possessive DP phase (58b), being, thus, unavailable for further syntactic operations.

(58) a. John ${ }_{1}$ loves his mother

b. [ loves [DP [John his] mother]]]

For detailed critical review of Kayne's proposal, see Safir (2008).

Zwart (2002) assumes Kayne's analysis, but reduces its scope to anaphors. According to him, anaphors are interpreted as correferent to their antecedents because the two elements form a syntactic unit during the derivation and, as a result, the anaphors checks an uninterpretable [+coreferential] feature, which at $\mathrm{PF}$ is morphologically realized as a reflexive pronoun. As for pronouns, the author argues that coreferentiality with pronouns is not a syntactic process. Contrary to Kayne, it is assumed that all cases of pronominal coreference are accidental. There is no difference between bound and deictic pronouns. This analysis, thus, requires extra, non-syntactic machinery to explain principle B effects. 


\section{Conclusions and remarks}

We have not yet achieved explanatory adequacy for binding. There is no fitting minimalist account for the distribution of anaphors, pronouns and R-expressions yet.

However, I believe the review above indicates that binding results from narrow syntax computations. Placing the binding principles at a representational level is part of the GB tradition, and, maintaining this tradition might force us to shoulder mechanisms extraneous to the minimalist methodology adopted so far. The process of coindexation itself and the delimitation of binding domains are not accommodated by representational analyses, unless a modular view of binding is assumed. Also, the empirical evidence for binding as conditions on LF is slim and weak. Chomsky (1993) and Fox and Nissenbaum (2004) based their arguments solely on reconstruction effects. However, these effects can be captured derivationally, once the copy theory of movement is assumed. In effect, Chomsky (1993) had to adopt LF-movement to account for the distribution of anaphors versus pronouns and R-expressions, emptying his own arguments based on reconstruction effects. Altogether the facts indicate that binding is an effect of syntactic computations.

This conclusion is latent since 1988, when Belletti and Rizzi pointed out that Principle A applied at all levels of presentation from D-structure to LF. If Principle A applies everywhere, it is probably a dynamic process, rather than a static filter or condition. Thus, I believe syntactic accounts are on the right track, but I am not sure we should take bound pronouns to be grammatical formatives, as proposed by Hornstein $(2000,2006)$ or generalize movement to cases of accidental coreferences, as done by Kayne (2002).

At the same time, exceptions to Principle $\mathrm{C}$ effects, the existence of logophoric anaphors and the pervasiveness of accidental coreference with pronouns signal that, in its totality, the coreferentiality phenomenon involves the interlocks between syntax and pragmatics. As for anaphors, Bruening (2018) presents interesting evidence based on VP ellipsis that the interpretation of nonlogophoric anaphors involves Pragmatics.

Nevertheless, analyses anchored on pragmatics alone (e.g., Schlenker's (2005) Minimize Restrictor's! Principle) cannot account for structural restrictions on binding, c-command and locality; and analyses based solely on syntax cannot accommodate accidental coreference, exceptions to Principles C \& A and logophoricity.

To have a glimpse of the role played by the syntax-pragmatic interface, let us consider Principle $\mathrm{C}$ effects again. Sensibility to Principle $\mathrm{C}$ is not black on white. It seems to vary from case to case, being more severe in cases in which the coindexed element is semantically richer than its antecedent. The following degree of acceptability has been reported on the literature (Schlenker, 2005, p. 386; Johnson, 2019, p. 4): 
(59) a. The woman ${ }_{1}$ met someone who admires her

b. ?? The woman ${ }_{1}$ met someone who admires the woman 1

c. ?? The widow ${ }_{1}$ met someone who admires the woman 1

d. ${ }^{\star}$ She ${ }_{1}$ met someone who admires the woman

e. ${ }^{\star}$ The woman 1 met someone who admires Jane

f. *The woman ${ }_{1}$ met someone who admires the widow $_{1}$

The contrasts in (59) suggest that the flow of semantic information between coindexed elements is somehow controlled, such that antecedents have to be more informative than the elements they are coindexed to. In (59d-f), the antecedents are less informative than the DPs coindexed to it. She in (59d), for example, has less information than the woman: the denotation of the DP the woman includes being an adult and a female; the denotation of she includes being a female, but not being an adult.

Wasow (1972) proposed the following constraint on antecedent-anaphor dependencies:

\section{(60) novelty constraint}

An anaphor may not introduce any presuppositions not associated with its antecedent

(Wasow, 1972, p. 178)

Johnson's (2019) modeled Wasow's constraint in terms of accommodation of presuppositions, suggesting that Principle $\mathrm{C}$ blocks a DP introducing a richer presupposition from being accommodated by a DP projecting less presupposition.

This reasoning is arguably necessary to understand the degrees of acceptability reported in (60), and why Principle C does not apply to elements loaded with emotive content, such as epithets (Schelenker, 2005). Under Johnson's analysis, epithets contain a not-at-issue comment, and, as a result, they do not require the process of presupposition accommodation that regular definite DPs do. Nonetheless, Principle $\mathrm{C}$ cannot be totally reduced to effects of presupposition accommodation. As discussed above, c-command and locality are syntactic notions, defining syntactic operations such as Move and Agree. Therefore, the fact that the definition of binding principles make reference to c-command and domains (locality) indicates that syntax has a share of the binding phenomenon.

The conclusion we can draw from the existing evidence is the following: syntax provides the mechanisms/operations responsible for establishing binding relations, while pragmatics regulates the naturalness of these relations vis à vis information from the background context, supplying, if necessary, mechanisms for the interpretation of elements whose denotation is not grounded through syntactic means.

This might be a humble conclusion, but it has far-reaching implications for the architecture of grammar and suggests that many of our future breakthroughs on binding will be about the interlocks of the syntax-pragmatics interface. 


\section{Notes}

1. Here I will focus on discussing Kayne's analysis for pronouns, leaving aside his discussion on anaphors and R-expressions.

2. Movement to non-c-commanding positions has been suggested in the literature, as in Nunes' (1995) account to parasitic gaps. However, in these analyses, the final landing site of the moved element (i.e., the head of the chain) has to be a c-commanding position. Nunes models this $\mathrm{c}$-command constraint as a condition on chain formation.

\section{References}

Aoun, J. (2000). Resumption and last resort. DELTA, 16, 13-43.

Asudeh, A. (2004). Resumption as resource management. [Doctoral dissertation]. Stanford University.

Belletti, A., \& Rizzi, L. (1988). Psych verb and theta-theory. Natural Language and Linguistic Theory, 6, 291-352.

Beltrama, A., \& Xiang, M. (2016). Unacceptable but comprehensible: the facilitation effect of resumptive pronouns. Glossa: A Journal of General Linguistics, 29, 1-24.

Bruening, B. (2018). In defense of the classical Binding Theory: combining precede-andcommand with the presuppositional approach to binding condition A. Unpublished Manuscript, University of Delaware. https://pdfs.semanticscholar.org/5fb6/ ae2f4512fa1461007dd93cd49d4f9f47bc18.pdf.

Chein, Y-C. and Wexler, K. (1990). Children's knowledge of locality conditions in binding as evidence for the modularity of syntax and pragmatics. Language Acquisition, 1, 225-295.

Chomsky, N. (1976). Conditions on rules of grammar. Linguistic Analysis, 2, 303-351.

Chomsky, N. (1980). Rules and representations. Oxford: Blackwell.

Chomsky, N. (1981). Lectures on government and binding. Dordrecht: Foris.

Chomsky, N. (1982). Some concepts and consequences of the theory of government and binding. Cambridge, MA: The MIT Press.

Chomsky, N. (1986). Knowledge of language: its nature, origin and use. New York: Praeger.

Chomsky, N. (1991). Some notes on economy of derivation and representation In R. Freidin (Ed.), Principles and parameters in comparative grammar (pp. 417-544). Cambridge, MA: The MIT Press.

Chomsky, N. (1993). A minimalist program for linguistic theory. In K. Hale \& S. J. Keyser (Eds.), The view from building 20: Essays in linguistics in honor of Sylvain Bromberger (pp.1-52). Cambridge, MA: The MIT Press. Reprinted as Chapter 3 of Chomsky, N. 1995. The Minimalist Program. Cambridge, MA: The MIT Press.

Chomsky, N. (1995). The Minimalist Program. Cambridge, MA: The MIT Press.

Chomsky, N. (2001). Derivation by phase. In Michael Kenstowicz (Ed.), Ken Hale: a life in language (pp. 1-52). Cambridge, MA: The MIT Press.

Chomsky, N., \& Lasnik, H. (1993). The theory of principles and parameters. In J. Jacobs, A. von Stechow, W. Sternefeld, \& T. Vennemann. (Eds.), Syntax: an international handbook of contemporary research Vol 1 (pp. 506-569). Berlin: Walter de Gruyter.

Fiengo, R., \& Higginbotham, J. (1981). Opacity in NP. Linguistic Analysis, 7, 395-421.

Frampton, J. (1991). Relativized minimality: a review. The Linguistic Review, 8, 1- 46. 
Fox, D., \& Nissenbaum, J. (2004). Condition A and scope reconstruction. Linguistic Inquiry, 35, 475-485.

Grodzinsky, Y., \& Reinhart, T. (1993). The innateness of binding and of coreference. Linguistic Inquiry, 24, 69-101.

Heestand, D., Xiang, M., \& Polinsky, M. (2011). Resumption still does not rescue islands. Linguistic Inquiry, 42, 138-152.

Heinat, F. (2006). Probes, pronouns, and binding in the Minimalist Program. [Doctoral dissertation]. Lund University.

Heim, I. (1998). Anaphora and semantic interpretation: A reinterpretation of Reinhart's approach. In U. Sauerland \& O. Percus. (Eds.), The interpretive tract. MIT Working Papers in Linguistics 25 (pp. 205-246). Cambridge, MA: MITWPL, MIT.

Heycock, C. (1995). Asymmetries in reconstruction. Linguistic Inquiry, 24, 103-138.

Hicks, G. (2009). The derivation of anaphoric relations. Amsterdam: John Benjamins.

Hornstein, N. (2000). Move! A minimalist theory of construal. Oxford: Blackwell.

Hornstein, N. (2006). Pronouns in a minimalist setting. University of Maryland Working Papers in Linguistics, 14, 47-80.

Huang, C.T. J. (1983). A note on the binding theory. Linguistic Inquiry, 14, 554-561.

Jackendoff, R. (1972). Semantic interpretation in generative grammar. Cambridge, MA: The MIT Press.

Johnson, K. (2012). Pronouns vs. definite descriptions. In M. Becker, M. J. Grinstead, \& and J. Rothman. (Eds.), Generative linguistics and acquisition: studies in honor of Nina M. Hyams (pp. 157-184). Amsterdam: John Benjamins.

Johnson, K. (2019). Principle C. Unpublished manuscript. UMass. https://people. umass.edu/kbj/homepage/Content/PC_final.pdf.

Kayne, R. S. (1972). Subject inversion in French interrogative. In J. Casagrande \& B. Sacink. (Eds.), Generative studies in Romance languages (pp. 70-126). Rowley, MA: Newbury House.

Kayne, R. S. (1994). The antisymmetry of syntax. Cambridge, MA.: The MIT Press.

Kayne, R. S. (2002). Pronouns and their antecedents. In S. D. Epstein, \& T.D. Seely. (Eds.), Derivation and explanation in the Minimalist Program (pp. 133-166). Backwell.

Lebeaux, D. (1998). Where does the binding theory apply? Technical Report 98-044. NEC Research Institute, Princeton.

Lees, R. B., \& Klima, E. S. (1963). Rules for English pronominalization. Language, 39,17-28.

Nissenbaum, J. (2000). Investigations of covert phrase movement. [Doctoral dissertation]. MIT.

Nunes, J. N. (1995). The copy theory of movement and linearization of chains in the Minimalist Program. [Doctoral dissertation]. University of Maryland.

Polinsky, M., Clements, L. E., Morgan, A. M., Xiang, M., \& Heestand, D. (2013). Resumption in English. In J. Sprouse, \& N. Hornstein. (Eds.), Experimental syntax and island effects (341-360). Cambridge: Cambridge University Press.

Reinhart, T. (1976). The syntactic domain of anaphora. [Doctoral dissertation]. MIT.

Reinhart, T. (1983). Anaphora and semantic interpretation. London: Croom Helm. 
Reinhart, T. (2006). Interface strategies: optimal and costly computations. Cambridge, MA: The MIT Press.

Reuland, E. (2011). Anaphora and language design. Linguistic Inquiry Monographs. The MIT Press.

Ross, J. (1967). Constraints on variables in syntax. [Doctoral dissertation]. MIT.

Safir, K. (2008). Coconstrual and narrow syntax. Syntax, 11, 330-355.

Schlenker, P. (2005). Minimize restrictors! (Notes on definite descriptions, condition $\mathrm{C}$ and epithets). In E. Maier, Corien Bary, \& J. Huitink. (Eds.), Proceedings of Sinn und Bedeutung (pp. 385-416). Nijmegen: NCS.

Shlonsky, U. (1992). Resumptive pronouns as a last resort. Linguistic Inquiry, 23, 443468.

Uriagereka, J. (1995). Aspects of the syntax of clitic placement in Western Romance. Linguistic Inquiry, 26, 79-123.

Uchiumi, T. (2006). Binding and control:a unified approach. [Doctoral dissertation]. McGill University.

Wasow, T. (1972). Anaphoric relations in English. [Doctoral dissertation]. MIT.

Zwart, J. W. (2002). Issues relating to a derivational theory of binding. In S. D. Epstein, \& T. D. Seely. (Eds.), Derivation and explanation in the Minimalist Program (pp. 269-304). Oxford: Blackwell.

Recebido em: 15/05/2020

Aceito em: 24/07/2020 
